\title{
Do we Trust the Polymerase Chain Reaction Test Result in Children to Diagnose COVID-19? A Case Report of COVID-19
}

\author{
Amir Nasimfar ${ }^{1}$, Rohollah Valizadeh ${ }^{2,3}$, Mohammad Nanbakhsh $^{4 \star}$ \\ ${ }^{1}$ Department of Pediatric, Shahid Motahari Hospital, Urmia University of Medical Sciences, Urmia, Iran; ${ }^{2}$ Student Research \\ Committee, School of Public Health, Iran University of Medical Sciences, Tehran, Iran; ${ }^{3}$ Nickan Research Institute, Isfahan, \\ Iran; ${ }^{4}$ Department of Pulmonology, Shahid Motahari Children Hospital, Urmia University of Medical Sciences, Urmia, Iran
}

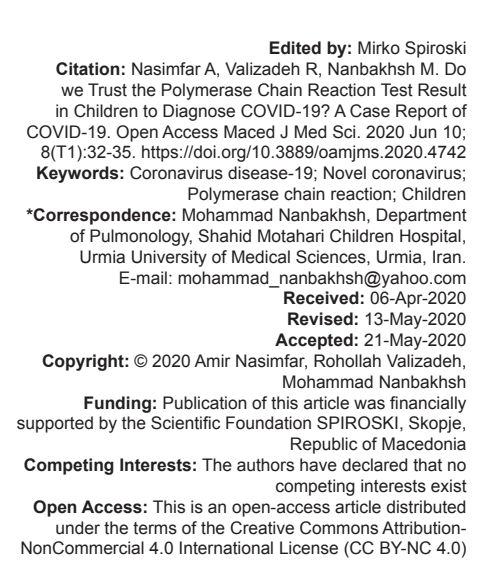

\section{Abstract}

BACKGROUND: Coronavirus disease-19 (COVID-19) resulted in widespread concern in global public health and has a bad prognosis despite drug therapy.

CASE REPORT: The patient was an 11-year-old girl referred to a children hospital with a dry cough, fever, and headache symptoms, without comorbidity. She was hospitalized following the results of high-resolution computed tomography (HRCT). The patient was treated with ceftriaxone $1 \mathrm{~g}$ every $12 \mathrm{~h}$ and the oseltamivir capsule $45 \mathrm{mg}$ every $12 \mathrm{~h}$ and azithromycin $250 \mathrm{mg}$ tablet once daily and $200 \mathrm{mg}$ hydroxychloroquine tablet every $12 \mathrm{~h}$ for a total of 5 days. After 5 days, the patient had suitable chest status and then was discharged. Azithromycin for 5 days and hydroxychloroquine for 10 days were prescribed for the patient to take at home. The patient's polymerase chain reaction (PCR) was negative at baseline through the nasopharyngeal swap, but HRCT of the patient's was completely consistent with COVID-19 accompanied by consolidation and ground-glass opacity in the left lower and right upper lobes.

CONCLUSION: The numerous technical errors in taking the nasopharyngeal swap were the main reasons for the negative PCR. The main lesson from this case report is the high sensitivity and specificity of HRCT compared to the PCR.
\end{abstract}

Introduction

Coronavirus disease-19 (COVID-19) is caused by severe acute respiratory syndrome coronavirus 2 (SARS-COV2) and is a causative agent of a potentially fatal disease that has caused widespread concern in the global public health. Coronavirus is one of the largest pathogens that mainly target the human respiratory tract, which has a bad prognosis despite drug therapy [1], [2].

Moreover, SARS-COV2 results in multiorgan failure, such as renal and liver failure [3], [4]. Regarding prevalence, these patients were associated with a wholesale market for seafood and wet animals in Wuhan, Hubei Province, China [5], [6]. Preliminary reports predicted the launch of a potential coronavirus epidemic with a basic reproduction number $(R 0)$ varying from 2.24 to 3.58 [7]. A study by Wang et al. showed that the ratio of male-to-female mortality was 3.25 to 1 , the median age of death was 75 years, the median time from the first symptoms to death was 14 days, and the median time from the initial symptoms to death above

70 years was shorter (11.5 days) than in people under 70 years of age (20 days). These findings suggest that the disease may progress more rapidly in adults than in young people [8].

$\mathrm{Li}$ et al. reported the mean age of 59 years for coronavirus-positive patients, of which $56 \%$ were men, the mean incubation period was 2.5 days, and almost half of the adult patients were 60 years and older [9]. The treatment of coronavirus in most cases is unnecessary because most patients have mild or moderate symptoms. However, it may be necessary to identify an etiological factor in epidemiological studies, especially during epidemic outbreaks. Since the novel coronavirus-2019 has not been found in humans before, no specific vaccine or treatment has been provided. In the current state of emergency, the number of cases is rapidly increasing. Therefore, it is important to diagnose all suspected cases as soon as possible and to remove them quickly to cutoff the source of the infection. New diagnostic solutions, including reverse transcription PCR and microscopic-based measurements, may be effective in monitoring epidemiological measures, along with preventive measures [10]. Coronavirus Novin2019 nucleic acids can be detected in samples such 
as nasopharyngeal swabs, sputum, lower respiratory tract secretions, blood, and feces [11], [12]. Therefore, we present a case report of different radiologic findings apart from PCR results.

\section{Case Presentation}

The patient was an 11-year-old girl referred to a children hospital with a dry cough, fever, and headache symptoms, without comorbidity, and with a history of adenoidectomy and ventilation tube implantation in both ears 9 months ago. She was hospitalized following the results of high-resolution computed tomography (HRCT) and imaging due to the aggravation of coughs. At the time of admission, height, weight, $\mathrm{Spo}_{2}$, respiratory rate, heart rate, and axillary temperature were $145 \mathrm{~cm}, 24 \mathrm{~kg}, 97 \%$ (on room air), 17 breaths/ min, 97 beats $/ \mathrm{min}$, and $38.5^{\circ} \mathrm{C}$, respectively. Laboratory results were as following

C-reaction protein $=+1$, white blood cell (WBC): $5200 / \mathrm{mm}^{3}$, lymph: $17 \%$, neut: $75 \%$, platelet) $=216,000$, hemoglobin: $12.5 \mathrm{mg} / \mathrm{dl}$, aspartate aminotransferase $(A S T)=30 \mathrm{lu} / \mathrm{l}$, alanine transaminase $(A L T)=35 \mathrm{lU} / \mathrm{l}$, alkaline phosphatase $=135 \mathrm{IU} / \mathrm{l}$, prothrombin time $=13 \mathrm{~s}$, partial thromboplastin time $=45 \mathrm{~s}$, international normalized ratio $=1.1$, serum calcium $(\mathrm{Ca})=8.8 \mathrm{mg} / \mathrm{dl}$, $25(\mathrm{oH})$ Vitamin D level $=52 \mathrm{ng} / \mathrm{ml}$, blood urea nitrogen $=$ $8 \mathrm{mg} / \mathrm{dl}$, creatinine $(\mathrm{Cr})=0.6 \mathrm{mg} / \mathrm{dl}$, erythrocyte sedimentation rate $=30 \mathrm{~mm} / \mathrm{hand}$, and lactate dehydrogenase $=461 \mathrm{IU} / \mathrm{L}$.

The patient was treated with ceftriaxone $1 \mathrm{~g}$ every $12 \mathrm{~h}$ and the oseltamivir capsule $45 \mathrm{mg}$ every $12 \mathrm{~h}$ and azithromycin $250 \mathrm{mg}$ tablet once daily and $200 \mathrm{mg}$ hydroxychloroquine tablet every $12 \mathrm{~h}$ for a total of 5 days. After 5 days, the patient had suitable chest status and then was discharged. Azithromycin for 5 days and hydroxychloroquine for 10 days were prescribed for the patient to take at home.

The patient's PCR was negative at baseline through the nasopharyngeal swap. HRCT of the patient's, which was reported by two radiologists, was completely consistent with COVID-19.

In Iran, there is no kit to detect coronavirus antibodies ( $\lg M$ and $\lg G$ ). The patient had previously been visited by an otorhinolaryngologist and had no upper airway problems and most of the symptoms were in the lower airway.

Due to the absence of respiratory distress and $\mathrm{Spo}_{2}$ above $94 \%$, blood gas was not taken from the patient. Due to the good general condition, the PCR test was not taken after discharge and was quarantined for only 2 weeks. Due to a large number of false negatives in the nasopharyngeal swab sample and the failure to obtain the correct sample or CT scan based on COVID19, which was reported by two radiologists, the PCR test and CT were not performed again.

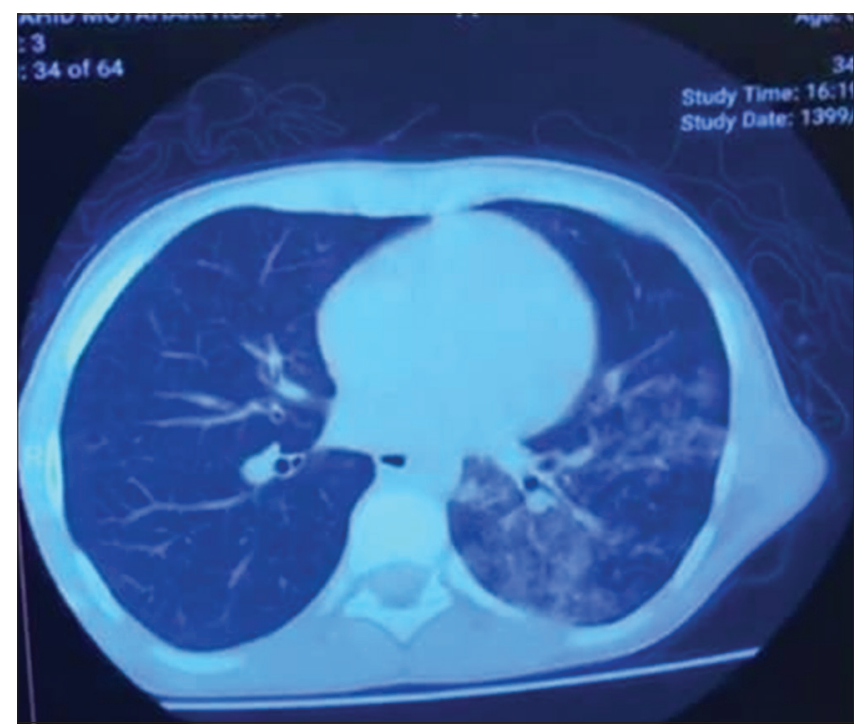

Figure 1: Consolidation and ground-glass opacity in the left lower lobe in high-resolution computed tomography

Figure 1 represents a consolidation and ground-glass opacity (GGO) in the left lower lobe. Figure 2 represents consolidation and GGO in the right upper lobe. Figure 3 shows no significant findings in the chest-X ray.

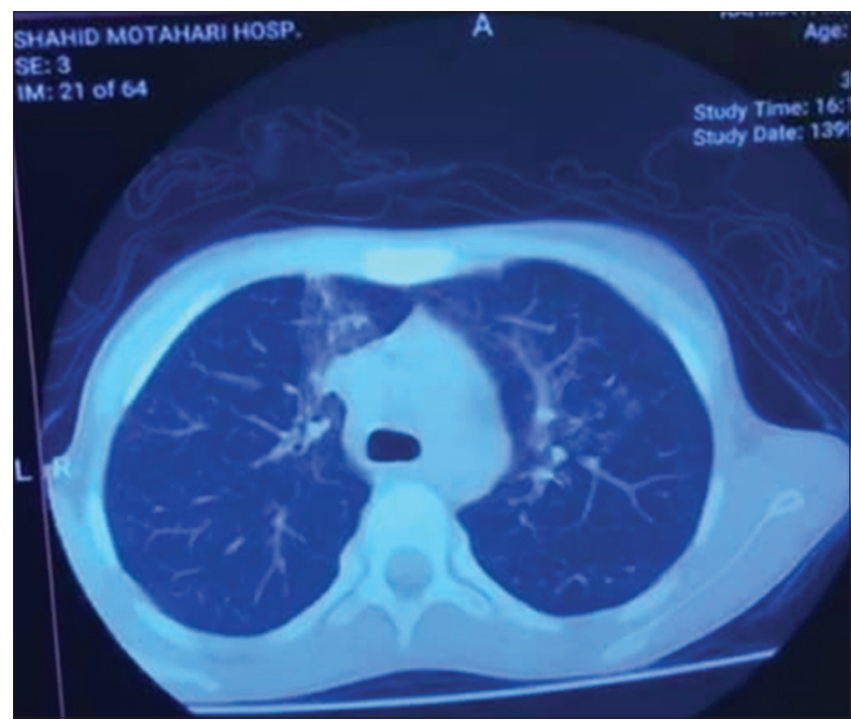

Figure 2: Consolidation and ground-glass opacity in the right upper lobe in high-resolution computed tomography

\section{Discussion}

Guan et al. reported 1099 cases of the novel 2019 coronavirus infection. They found that fever (78.9\%) and cough $(67.7 \%)$ were the most common symptoms. Abnormalities in CT images of the chest were observed in $96 \%$ of patients infected with the novel coronavirus-2019, 


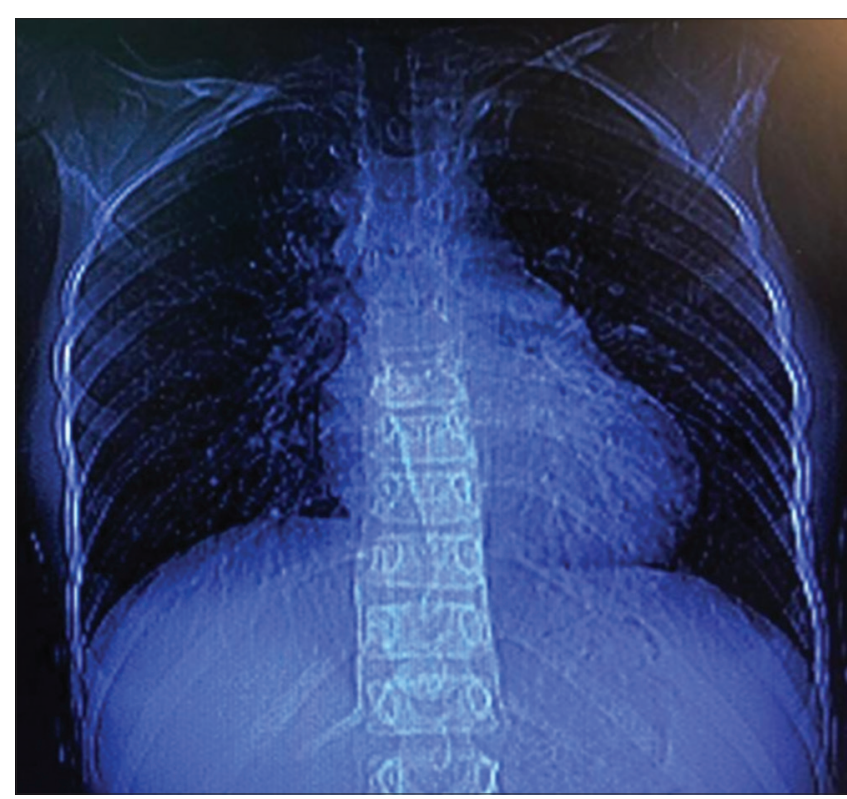

Figure 3: Normal chest-X ray of the patient

and Iymphocytopenia was recorded in $82.1 \%$ of them [9]. Our case was the same indicating that dry cough and fever can be common in the children too. WBC of $5200 / \mathrm{mm}^{3}$, lymph of $17 \%$, and neut of $75 \%$ showed lymphocytopenia of our case. In some studies, it has been reported that chest X-rays do not have enough sensitivity and specificity; thus, CT scans should be done like our case [13], [14], [15]. In the present case, chest X-ray was normal and could not detect COVID-19; then, we had no choice to check the CT scan of the patients. In the assessment of HRCT, we found that the lung had consolidation and GGO in the right upper and left lower lobes. In spite of the negative result of PCR, the radiologic findings approved COVID-19. Therefore, clinicians should check CT to approve the definite diagnosis of COVID-19. Hence, the majority of patients infected with the novel coronavirus-2019 can be diagnosed by CT. The fact that "children are not very susceptible" may jeopardize their health. Children should be prevented to have a close contact with the epidemic area and people [16], [17].

Huang et al. found that $98 \%$ of patients with COVID-19 had a fever. They reported that $76 \%$ of patients had a cough with dyspnea. Furthermore, a small number of patients had expectoration sputum. Laboratory tests showed that $25 \%$ of infected patients had leukopenia and $64 \%$ had lymphocytopenia. AST levels were elevated in $37 \%$ of patients. Abnormalities in chest CT images were observed in $100 \%$ of patients. GGO and consolidation areas were found in $37 \%$ of the lungs on both sides of infected patients [18]. The findings of CT of the present case were consistent with the study of Huang et al. In the present case, liver function tests were normal ( $A S T=30 \mathrm{lu} / \mathrm{l}, A L T=35 \mathrm{IU} / \mathrm{l}$, and $A L O=135 \mathrm{IU} / \mathrm{I})$, in such a way that was inconsistent with the study by Huang et al. [18].

\section{Conclusion}

The number and severity of pulmonary involvement in children are lower than adults based on Chinese and the previous articles. In our case, the severity of the symptoms was mild, and the numerous technical errors in taking the nasopharyngeal swap were the main reasons for the negative PCR, but HRCT apparently showed COVID-19. The main lesson from this case report is the high sensitivity and specificity of HRCT compared to the PCR.

\section{References}

1. Dadashzadeh $\mathrm{N}$, Farshid $\mathrm{S}$, Valizadeh $\mathrm{R}$, Nanbakhsh $\mathrm{M}$, Rahimi MM. Acute respiratory distress syndrome in COVID-19 disease. Immunopathol Persa. 2020;6(2):e16.

2. Valizadeh R, Dadashzadeh N, Zakeri R, Kelllner SJ, Rahimi MM. Drug therapy in hospitalized patients with very severe symptoms following COVID-19. J Nephropharmacol. 2020;9(2):e21.

3. Valizadeh R, Baradaran A, Mirzazadeh A, Bhaskar LV Coronavirus-nephropathy; renal involvement in COVID-19. J Renal Inj Prev. 2020;9(2):e18. https://doi.org/10.34172/ jrip.2020.18

4. Mubarak M, Nasri N. COVID-19 nephropathy; an emerging condition caused by novel coronavirus infection. J Nephropathol. 2020;9(3):e21. https://doi.org/10.34172/ jnp.2020.21

5. Bogoch II, Watts A, Thomas-Bachli A, Huber C, Kraemer MU, Khan K. Pneumonia of unknown etiology in Wuhan, China: Potential for international spreadvia commercial air travel. J Trav Med. 2020;27(2):taaa008. https://doi.org/10.1093/jtm/taaa008 PMid:31943059

6. Lu H, Stratton CW, Tang YW. Outbreak of pneumonia of unknown etiology in Wuhan China: The mystery and the miracle. J Med Virol. 2020;92(4):401-2. https://doi.org/10.1002/jmv.25678 PMid:31950516

7. Zhao S, Lin Q, Ran J, Musa SS, Yang G, Wang W, et al. Preliminary estimation of the basic reproduction number of novel coronavirus (2019-nCoV) in China, from 2019 to 2020: A datadriven analysis in the early phase of the outbreak. Int $\mathrm{J}$ Infect Dis. 2020;92:214-7. https://doi.org/10.1101/2020.01.23.916395 PMid:32007643

8. Wang W, Tang J, Wei F. Updated understanding of the outbreak of 2019 novel coronavirus (2019-nCoV) in Wuhan, China. J Med Virol. 2020;92(4):441-7. https://doi.org/10.1002/jmv.25689

9. Li Q, Guan X, Wu P, Wang X, Zhou L, Tong Y, et al. Early transmission dynamics in Wuhan, China, of novel coronavirusinfected pneumonia. N Engl J Med. 2020;382(13):1199-207. PMid:31995857

10. Forouzesh $M$, Azadeh $R$, Valizadeh $R$, Dadashzadeh $N$, Mirzazadeh A. Clinical display, diagnostics and genetic implication of novel coronavirus (COVID-19). Eur Rev Med Pharmacol Sci. 2020;24(8):4607-15. PMid:32374001

11. Emery SL, Erdman DD, Bowen MD, Newton BR, Winchell JM, MeyerRF, et al. Real-time reverse transcription-polymerase chain reaction assay for SARS-associated coronavirus. Emerg Infect Dis. 2004;10(2):311-6. https://doi.org/10.3201/eid1002.030759 PMid: 15030703 
12. Gaunt ER, Hardie A, Claas EC, Simmonds P, Templeton KE. Epidemiology and clinical presentations of the four human coronaviruses 229E, HKU1, NL63, and OC43 detected over 3 years using a novel multiplex real-time PCR method. $J$ Clin Microbiol. 2010;48(8):2940-7. https://doi.org/10.1128/ jcm.00636-10

PMid:20554810

13. Qiu H, Wu J, Hong L, Luo Y, Song Q, Chen D. Clinical and epidemiological features of 36 children with coronavirus disease 2019 (COVID-19) in Zhejiang, China: An observational cohort study. Lancet Infect Dis. 2020;20(6):689-96. https://doi. org/10.1016/s1473-3099(20)30198-5

14. Le HT, Nguyen LV, Tran DM, Do HT, Tran HT, Le YT, et al. The first infant case of COVID-19 acquired from a secondary transmission in Vietnam. Lancet Child Adolesc Health. 2020;4(5):405-6. https://doi.org/10.1016/s2352-4642(20)30091-2

PMid:32213326

15. Liu W, Zhang Q, Chen J, Xiang R, Song H, Shu S, et al. Detection of Covid-19 in children in early January 2020 in Wuhan, China. N Engl J Med. 2020;382(14):1370-1. https://doi.org/10.1056/ nejmc2003717

PMid:32163697

16. Jahromi AH, Mazloom S, Ballard DH. What the European and American health care systems can learn from China COVID19 epidemic; action planning using purpose designed medical telecommunication, courier services, home-based quarantine, and COVID-19 walk-in centers. Immunopathol Persa. 2020;6(2):e17. https://doi.org/10.1016/j.tmaid.2020.101676

17. Ghelichi-Ghojogh M, Kalteh EA, Fararooei M. Coronavirus disease 2019; epidemiology and recommendations. J Prev Epidemiol. 2020;5(1):e01.

18. Huang $\mathrm{C}$, Wang $\mathrm{Y}$, Li X, Ren L, Zhao J, Hu Y, et al. Clinical features of patients infected with 2019 novel coronavirus in Wuhan, China. Lancet. 2020;395(10223):497-506. https://doi. org/10.1016/s0140-6736(20)30183-5

PMid:31986264 